\title{
Commentary: Minimally invasive valve surgery: How to get from Houston to Leipzig
}

\author{
Michael Mack, MD
}

From the Cardiovascular Service Line, Baylor Scott \& White Health, Dallas, Tex.

Disclosures: Author is uncompensated co-principal investigator of research trials for Abbott, Edwards Lifesciences, and Medtronic.

Received for publication Nov 15, 2018; accepted for publication Nov 15, 2018; available ahead of print Dec 28, 2018.

Address for reprints: Michael Mack, MD, 1100 Allied Dr, Plano, TX 75093 (E-mail: Michael.mack@ bswhealth. org).

J Thorac Cardiovasc Surg 2019;157:1966-7

$0022-5223 / \$ 36.00$

Copyright (c) 2018 by The American Association for Thoracic Surgery

https://doi.org/10.1016/j.jtcvs.2018.11.060

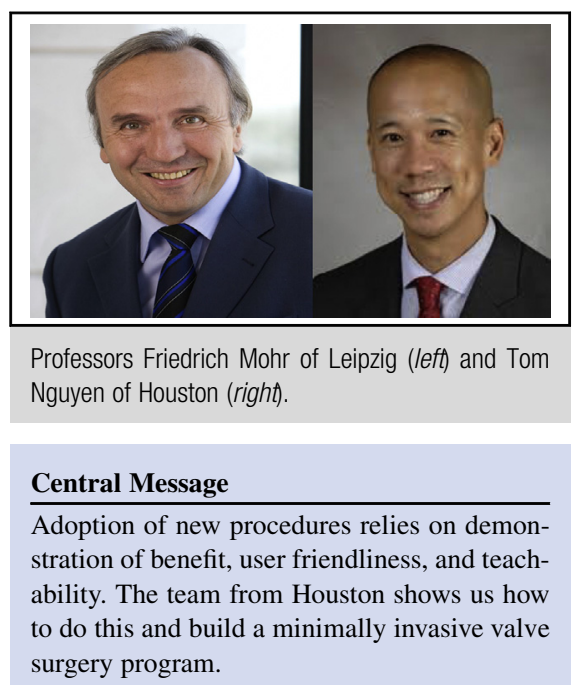

See Article page 1958.
Minimally invasive surgery has been widely adopted in a number of surgical specialties, including general surgery, bariatric surgery, colorectal surgery, urology, and thoracic surgery. Less-invasive surgical procedures are clearly preferred by patients and their referring physicians because of less systemic physiologic insult and pain, leading to quicker recovery and return to activities. The adoption of minimally invasive valve surgery, however, has been slower than in these other surgical subspecialties. Approximately $15 \%$ of mitral and aortic valve operations are now performed by a minimally invasive approach, an adoption rate that has not changed significantly during the past few years. Why has the adoption of minimally invasive valve surgery been slower than with other procedures? The adoption of any new medical procedure is based on 3 tenets: demonstration of benefit, user (operator) friendliness, and teachability. To some degree, failure to meet all these factors has slowed the adoption of minimally invasive valve surgery.

In this issue of the Journal, Nissen and colleagues ${ }^{1}$ from Nguyen's Houston team give us their detailed "playbook" for starting and building a successful minimally invasive valve surgery program that begins to address these 3 adoption obstacles. The article is comprehensive and describes all aspects of initiating a successful program. The programmatic approach described is quite exhaustive, but a few of the basic tenets are worth highlighting. First, a program needs a leader who is a visionary and can offer dynamic leadership and build a successful team. This leader must already be experienced in valve surgery and cannot be learning valve repair and replacement techniques while building a minimally invasive program. Nissen and colleagues ${ }^{1}$ describe a number of educational options by which the surgeon leader can gain this experience. Once this leader is identified and becomes committed, a team needs to be built around that surgeon. The surgeon needs to instill confidence in this team, which includes surgical first assistants,




patience, and the ability to be introspective and reflective, especially when the inevitable stumbles occur. By honest self-assessment and team engagement in critical review of outcomes and issues, robust program building occurs. I am reminded of the early days of minimally invasive mitral valve surgery, when Friedrich Mohr from Leipzig presented their initial experience at the American Association of Thoracic Surgery meeting in $1998 .^{2} \mathrm{He}$ was roundly criticized for the mortality and complications that occurred in their early experience with minimally invasive mitral surgery. He gave an honest and forthright presentation of the negative as well as the positive aspects and noted that Leipzig was presenting these results in the hope that everyone else could avoid the mistakes they made. That approach and that attitude from the leader of the program built the world's largest minimally invasive valve surgery program, which has persisted to this day and serves as the model for other programs to strive. The team from Houston gives us the playbook for how to start down this road.

\section{References}

1. Nissen AP, Nguyen S, Abreu J, Nguyen TC. The first 5 years: building a minimally invasive valve program. J Thorac Cardiovasc Surg. 2019;157:1958-65.

2. Mohr FW, Falk V, Diegeler A, Walther T, van Son JA, Autschbach R. Minimally invasive port-access mitral valve surgery. J Thorac Cardiovasc Surg. 1998;115: 567-74; discussion 574-6. 